Revista Mídia e Cotidiano

ISSN: 2178-602X

Artigo Seção Temática

Volume 14, Número 1, jan-abr de 2020

Submetido em: 09/11/2019

Aprovado em: 31/01/2020

\title{
Definição pela exclusão: apontamentos iniciais sobre os limites conceituais dos programas infantis
}

\section{Definition by exclusion: initial notes about the conceptual limits of children's TV programs}

\author{
Ariane HOLZBACH ${ }^{1}$ \\ Wagner DORNELLES ${ }^{2}$
}

\begin{abstract}
Resumo
Apesar de a noção de "programa infantil" ser tida como dada na cultura contemporânea, sua definição se complexifica se considerarmos que muitas crianças não consomem "programas infantis" ou os consomem modestamente, visto que frequentemente têm acesso a diversificados produtos "de adulto". Nossa proposta é compreender os limites conceituais e o caráter excludente do que se entende como programa infantil para, em seguida, entender como tais limites atuam na construção de infâncias contemporâneas. Defendemos uma mudança de olhar que considere a competência crítica das crianças e que leve em conta 1) o caráter eurocêntrico desses programas e 2) a relação simbiótica construída entre tais produtos e a cultura mercantil. Esta é a primeira etapa de um projeto mais amplo que investiga o consumo audiovisual de crianças que vivem em regiões periféricas, com pouco ou nenhum acesso a programas infantis.
\end{abstract}

Palavras-chave: Programa infantil. Televisão. Infância. Eurocentrismo.

\begin{abstract}
The definition of "children's TV programs" is taken as a given in contemporary culture. However, this category becomes complex if we consider that many children do not merely consume TV programs aimed at them as they often have access to diverse media products aimed at adults. Therefore, our first aim is to understand the conceptual limits and the excluding character of what is meant by children's TV programs. Following this, we attempt to understand the role that such limits play in the construction of contemporary childhood. We argue that we must change our views in relation to children, considering that they are reactive and critical individuals and taking into account 1) the Eurocentric character of children's programs and 2) the symbiotic relationship between contemporary

\footnotetext{
${ }^{1}$ Professora de Estudos de Mídia e do Programa de Pós-graduação em Comunicação da UFF. Doutora em Comunicação pela UFF com pós-doutorado em História pela UERJ. Coordenadora do AnimaMídia Grupo de Pesquisa em Desenhos Animados. E-mail: arianeh@id.uff.br. ORCID: 0000-0002-8548-0220.

${ }^{2}$ Mestre e doutorando em Comunicação pela UFF. E-mail: wsdornelles@ gmail.com. ORCID: 0000-00018023-9078.
} 
children's programs and a market culture. This is the first stage of a larger project that seeks to understand the audiovisual consumption of children living in peripheral regions of Brazil with little or no access to traditional children's programs.

Keywords: Children's TV programs. Television. Childhood. Eurocentrism.

\section{Introdução}

Programa infantil é um tipo de programa de televisão destinado e comercializado ao público infantil. É normalmente transmitido durante as manhãs e tardes, ou por vezes no começo da noite para crianças que frequentam a escola. O propósito de tais programas é em primeiro lugar o entretenimento, embora existam aqueles com conteúdo educativo (Fonte: Wikipedia, verbete Programa Infantil, acessado em: 3. jan. 2020).

A Wikipedia aglutina um senso comum enraizado em torno do que seria programa infantil. De acordo com a enciclopédia, "programa infantil”, em primeiro lugar, seriam produtos televisivos. Em segundo lugar, reuniriam um conjunto de produções midiáticas cuja função é a comercialização e o entretenimento, com pitadas de elementos pedagógicos. Levando em perspectiva o fato de a Wikipedia ser uma enciclopédia alimentada por uma rede colaborativa cujos verbetes passam por um complexo processo de validação da informação (GONÇALVES, 2014), trata-se de um espaço que diz muito sobre a maneira contemporânea de pensar e definir conceitos da vida cotidiana. Entretanto, tal definição é bastante problemática e ajuda a definir parte dos desafios existentes para compreensão dos produtos midiáticos consumidos pelas crianças.

Em primeiro lugar, o verbete contempla o audiovisual, mas exclui os produtos que estão fora da televisão, como é o caso do cinema e especialmente do YouTube, onde uma infinidade de gêneros, formatos e tipos de produtos são explorados por crianças, que cada vez mais são onipresentes nesse espaço. Em segundo lugar, o verbete define programa infantil inserindo o público apenas ao final do processo: às crianças é destinado um conjunto específico de conteúdos televisivos que, via de regra, não seriam produzidos por elas. Não caberia às crianças, assim, outros lugares no circuito comunicativo, como o de produtores ou de mediadores do conteúdo que consomem. Mais uma vez, o verbete “programa infantil" exclui, por exemplo, o papel fundamental dos youtubers mirins e de 


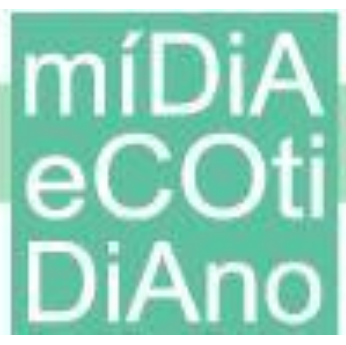

muitas outras crianças que frequentemente dominam variadas etapas do circuito comunicativo de produtos midiáticos dos mais heterogêneos.

O nosso interesse neste artigo é sobretudo compreender o caráter excludente existente em torno do que se define usualmente como programa infantil. Nossa investigação não aglutina necessariamente os produtores mirins de conteúdo, considerando que já existe um grupo de autores que vêm trazendo importantes contribuições nessa perspectiva, como Bragaglia e Ferreira (2016) e Tomaz (2017). A nossa maior preocupação consiste especificamente em um elemento que é mais naturalizado e que portanto é mais difícil, à primeira vista, de ser visualizado como sendo um problema: o fato de que as crianças com frequência consomem um grande conjunto de programas que não estão inseridos no que se considera socialmente como infantil. No extremo, boa parte das crianças brasileiras - quiçá a maior parte - não consome programas infantis tanto porque 1) não têm acesso a eles ou 2) estão inseridas em um contexto social/familiar que prioriza a expectatorialidade adulta. Integram esse grupo as crianças, por exemplo, que assistem às telenovelas e aos programas de auditório juntamente (ou não...) com pais e responsáveis, que vão ao cinema para assistir a filmes de suspense ou comédias românticas e que ficam acordadas de madrugada consumindo produções com alto caráter sexualizado e violento. Assim, como definir um conceito em torno de "programa infantil" considerando que um grande número de crianças consome exclusivamente ou em grande parte os conteúdos "de adultos"?

Esta é uma questão complexa que, sabemos, não pode ser entendida em plenitude ao longo de um artigo. Estudar o consumo midiático das crianças constitui não só uma forma de entender e mapear processos de transmediação (BUONANNO, 2008), ou as táticas para a participação no mundo atual (CERTAU, 1994), mas também de compreender o papel das crianças na construção e consumo dos conteúdos midiáticos, além de eventualmente mapear suas características na dinâmica familiar. Nossa proposta, nesse sentido, é iniciar uma reflexão sobre o que é definido como programa infantil especificamente no caso da mídia brasileira. Entendemos que este é o primeiro passo para, em momento posterior, fazermos uma cartografia em torno do tipo de consumo midiático que as crianças brasileiras fazem para além do que usualmente se considera "infantil". A proposta deste texto é conceitual e se insere em um projeto mais amplo, ainda em fase 


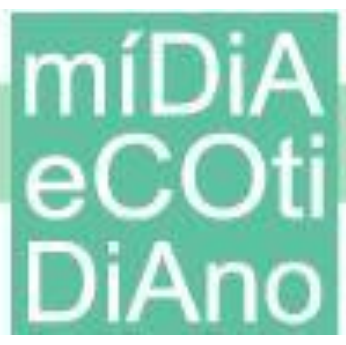

inicial, que objetiva entender o consumo audiovisual de crianças que vivem em regiões carentes do estado do Rio de Janeiro. O passo seguinte é fazer uma etnografia para entender as problemáticas envolvidas nesse consumo a partir do argumento que desenvolvemos no presente artigo: o que se entende usualmente como "programa infantill" não permite compreender as complexidades existentes em contextos nos quais as crianças não têm acesso a produções idealizadas para elas, frequentemente encontradas apenas na televisão por assinatura e no cinema, entre outros espaços elitizados e bastante segmentados de consumo audiovisual.

Nossa proposta, assim, é identificar o que socialmente se entende como programa infantil para, então, termos condições de mapear com consistência os variados tipos de consumo que as crianças fazem dos produtos audiovisuais. Neste artigo, dois caminhos são trilhados para o debate da temática: faremos inicialmente uma breve discussão sobre alguns limites do conceito contemporâneo de infância e a ligação desses limites com a cultura midiática para, em seguida, analisarmos o caráter excludente dos programas infantis sob duas óticas que se sobressaem na construção social desse fenômeno. De um lado, temos a consolidação de um olhar eurocêntrico em torno dos programas infantis e, de outro, temos a intrínseca relação existente entre esses programas e a cultura mercantil.

\section{Que olhar predomina sobre a infância?}

O imaginário contemporâneo em torno da infância é um fenômeno recente, fruto da Modernidade e da Revolução Industrial (STEINBERG; KINCHELOE, 2001). Entendido como uma construção social, esse imaginário tem sido problematizado desde o início do século XX, mas a partir de uma dinâmica argumentativa em boa medida linear que entende a infância como sendo o primeiro estágio da vida. Estudar a infância, neste cenário, configura-se como a compreensão e crítica de uma instituição que se mantém em constante mutação desde o século XVII. A consolidação do sistema estudantil, o processo de Revolução Industrial, o fim da escravidão e a independência das colônias europeias determinaram novas formas de sociabilidade. A orientação da sociedade para o futuro (HELLER, 2013) somada ao olhar psicanalítico, a incorporação da noção de preparo e a configuração da educação como pilar fundamental desse estágio da vida constituíram-se 


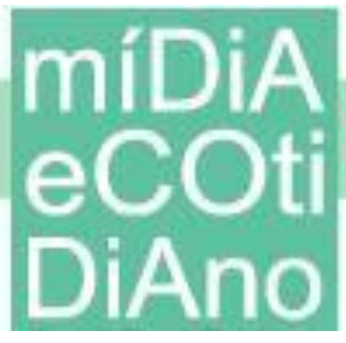

como elementos para a definição da infância como instituição idealizada. Tal fato cristaliza determinados cuidados relacionados a essa fase da vida, em que estruturas sociais e marcos legais tentam protegê-la num esforço de garantir a perpetuação de uma sociedade na qual as crianças "são o futuro" e, portanto, merecem cuidados que têm em vista a preservação do indivíduo em formação.

Paralelamente à consolidação da ideia de infância, houve a expansão das políticas de educação, modelo que não se expandiu de maneira igualitária. Grupos étnicos e sociais diferenciados passaram a incorporar os valores da infância idealizada por uma sociedade cada vez mais inclinada às perspectivas de progresso e orientada aos ideais europeus. No Brasil, este fato pôde ser observado através da criação do $\mathrm{ECA}^{3}$ - Estatuto da Criança e do Adolescente -, que estabelece garantias legais para a preservação desse estágio da vida. Políticas públicas específicas foram criadas e houve a consolidação/incorporação de grupos historicamente marginalizados no Sistema Educacional Brasileiro, principalmente após o governo de Getúlio Vargas ${ }^{4}$.

Esse pano de fundo dialoga com a identidade socialmente instituída na infância. Ao pensar a adolescência, Luciana Coutinho (2005) afirma que a constituição da identidade nessa etapa da vida ocorre a partir da ruptura com a família e a busca por grupos de reafirmação. Esta leitura, porém, tem sua base na constituição familiar tradicional. Há, entretanto, a criança que se encontra no centro tanto de dinâmicas familiares plurais, configuradas desde a ausência parental por questões laborais, quanto de dinâmicas familiares complexas em que o adulto que se constitui como referência está diluído em diversas figuras que permeiam a rotina da criança, como professores, tios, avós, vizinhos etc. Coutinho destaca, com base no pensamento freudiano, a ideia de representação e reafirmação que a saída da infância impõe ao sujeito, fruto de um trabalho intensivo de elaboração do laço social a partir das referências simbólicas transmitidas pela cultura e representadas pelos ideais. $\mathrm{O}$ adolescente é particularmente afetado pelos impasses relativos a essa transmissão, de modo que é crucial entender a importância das influências ainda na infância, e os impactos na formação identitária desse sujeito.

\footnotetext{
${ }^{3}$ O ECA foi criado em 1990 e estabelece uma série de normas para a proteção de crianças e adolescentes. No decorrer dos anos, novas medidas foram incorporadas.

${ }^{4}$ Disponível em: <http://www.planalto.gov.br/ccivil_03/leis/18069.htm>. Acesso em: 03 jan. 2020.
} 
A infância, assim, se destaca como objeto de interesse, mas exige um deslocamento no olhar. Apesar de todos os discursos de proteção que a circundam, percebe-se que se trata de um modelo hegemônico que não atende a todas as crianças. Há, pois, um grande distanciamento entre a infância discursiva, aquela idealizada pelos livros e demais instituições, e a prática, estabelecida no cotidiano. Aquelas que têm capital familiar suficiente, têm a preservação deste estágio da vida de acordo com valores estabelecidos socialmente. As demais, que porventura sejam destituídas desse capital, encontram-se numa difícil posição em que a proteção dos seus direitos básicos depende de um intricado sistema que se reveza entre o senso de responsabilidade do Estado e as benesses do mercado, algo bastante perceptível na produção midiática, como é o caso da popularização das plataformas midiáticas digitais.

Após a popularização da internet, houve uma mudança nos mapas de inclusão e, principalmente, nos de exclusão social. Conceitos como "nativo" ou "incluído" digital passaram a compor a realidade das crianças, assim como a expectativa de acesso e letramento digital desde a educação infantil (EMERA, 2014). De acordo com pesquisa realizada pela ESPM com autoria de Luciana Corrêa, 91\% dos jovens conectados utilizam o YouTube com frequência. A plataforma de vídeos superou os números do Instagram e do Facebook, que ficaram com 63\% e 61\%, respectivamente (CORRÊA, 2016). Tal fato se justifica pela grande quantidade de materiais disponíveis na plataforma.

Por outro lado, ainda temos um número imensurável de crianças destituídas de acesso que, muitas vezes, são invisibilizadas nos processos metodológicos das pesquisas científicas. É neste contexto que os meios de comunicação tradicional reconfiguraram seus conteúdos e pilares de consumo. Apesar de os dados apresentados pelo IBGE $^{5}$ apontarem que 64,7\% dos brasileiros utilizaram a internet em 2016, sabe-se que a falta de infraestrutura em dadas regiões e de capital para a manutenção do serviço dificultam o acesso. Neste cenário, a televisão aberta se mantém como um dos principais veículos de comunicação no Brasil. Ainda segundo o IBGE, 69 milhões de residências possuem

\footnotetext{
${ }^{5}$ Dados da matéria "Brasil tem 116 milhões de pessoas conectadas à internet, diz IBGE". Disponível em: <http://abre.ai/asjl>. Acesso em: 09 nov. 2019.
} 
aparelhos de televisão no país ${ }^{6}$. A redução gradativa e, por fim, a extinção da programação infantil na grade fixa da maior parte dos canais da televisão aberta brasileira (HOLZBACH, 2018) esbarra em uma série de fatores que delimitam e regulam os espaços da infância na sociedade. Um fato que foi anterior ao fim deste tipo de programação, mas que é digno de menção, foi a promulgação da Resolução 163 do Conanda - Conselho Nacional dos Direitos da Criança ${ }^{7}$ - que reconheceu como abusiva a publicidade dirigida ao público infantil.

Tal determinação atingiu diretamente a receita dos canais, já que a publicidade veiculada nos intervalos e até mesmo durante esse tipo de programação era voltada para as crianças. Nesse caso, salvo raras exceções, como TV Cultura, SBT e dados horários sem programação fixa que recebem o enxerto de desenhos animados considerados infantis, não há espaço determinado ou com preparo prévio de conteúdo para esse público. Por outro lado, Netflix e YouTube se tornaram as estruturas favoritas para estes conteúdos $^{8}$. Enquanto a Netflix, desde 2014, tem um menu exclusivo nomeado "Infantil", que reúne milhares de desenhos animados, novelinhas, filmes e séries supostamente destinadas às crianças, o YouTube oferece uma complexidade de tipos de conteúdo audiovisual bastante difusos e que são, a priori, categorizados como “infantil”. Nele, há desde canais autorais com conteúdos similares aos oferecidos pela Netflix até programas exibidos nos canais televisivos e nos cinemas, no passado e no presente, além de uma infinidade de conteúdo "amador", disponibilizado pelos usuários. Essa profusão de conteúdo não institucionalizado se divide entre canais oficiais de animações de grandes

\footnotetext{
${ }^{6}$ Dados da matéria "Pesquisa diz que, de 69 milhões de casas, só 2,8\% não têm TV no Brasil". Disponível em: <http://abre.ai/asjp> Acesso e: 9 nov. 2019.

${ }^{7} \mathrm{O}$ órgão, vinculado à Secretaria de Direitos Humanos da Presidência da República, categorizou como abusiva a publicidade dirigida ao público infantil sob a alegação de que fere a Constituição, o Estatuto da Criança e do Adolescente (ECA — Lei 8.069/1990) e o Código de Defesa do Consumidor (CDC — Lei 8.078/1990). De acordo com texto publicado no Portal do Senado Federal, "O artigo 37 do CDC, por exemplo, considera abusiva, entre outras, 'a publicidade que se aproveite da deficiência de julgamento e de experiência da criança ou que seja capaz de induzir o consumidor a se comportar de forma prejudicial ou perigosa à saúde'. Na Constituição, o artigo 227 diz que 'é dever da família, da sociedade e do Estado' assegurar à criança, ao adolescente e ao jovem, com absoluta prioridade, seus direitos e colocá-los a salvo de toda forma de negligência, discriminação, exploração, violência, crueldade e opressão. E o artigo 17 do ECA prevê o direito ao respeito, abrangendo, entre outros, a inviolabilidade da integridade física, psíquica e moral.” Disponível em: <http://bit.ly/2P5Lmre> Acesso em: 27 jan. 2020.

${ }^{8}$ Netflix e YouTube são apenas mencionados porque apresentam complexidades que não cabem no escopo e no espaço deste texto.
} 


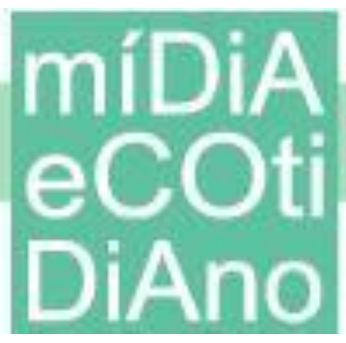

empresas, como Mauricio de Sousa Produções e Grupo Disney, e conteúdos não autorizados, que, diferentemente da Netflix, podem ser acessados sem a existência de um login ou assinatura do suporte, mas que, de qualquer forma, exigem a estrutura gramatical e tecnológica que permita o acesso aos vídeos. A existência e a força de espaços como Netflix e YouTube na exibição de conteúdo infantil exigem que repensemos a relação construída historicamente entre programa infantil e televisão (convencional, formada pelos canais abertos e por assinatura). Cabe destacar, ainda, que mesmo após a resolução 169 do Conanda, a publicidade ainda ocorre no ambiente digital sob a forma dos chamados unboxing ${ }^{9}$ ou diluída no conteúdo dos canais ${ }^{10}$.

De todo modo, há uma fatia do público infantil sem acesso doméstico à internet. A partir desse aspecto, torna-se necessário um estudo aprofundado que proponha o entendimento das práticas de consumo midiático e narrativas, tendo como fatores determinantes as questões locais tecnológicas e processos de significação do que é passível de consumo por este público. Além disso, deve-se problematizar o conceito de infância e a criança neste contexto.

\section{O embate entre a mídia e a infância}

No decorrer do século XX, alguns autores do campo da Comunicação manifestaram preocupações em torno da relação entre mídia e infância, mas mantiveram um olhar prioritariamente moderno, no qual a criança indefesa, imatura e em processo de formação cognitiva consumiria os produtos midiáticos sem qualquer ou com pouco posicionamento reativo ou crítico. De maneira geral, o olhar analítico parte das mídias para definir métodos de análises de diferentes processos. O deslocamento no olhar que propomos permite que a partir da perspectiva de uma infância atuante, ela apresente sua relação com as mídias. Este protagonismo, já anunciado por Clarice Cohn (2005), rompe com a tradição frankfurtiana, calcada nos pressupostos da alienação.

\footnotetext{
9 Consiste na abertura de embalagens em frente à câmera para mostrar a reação do ou da youtuber. Muitas vezes, são presentes enviados por empresas interessadas na publicidade do lançamento de algum produto.

${ }^{10} \mathrm{O}$ fim definitivo da publicidade infantil reduziria em $13 \%$ a receita de anunciantes. Mesmo após a determinação, que tem efeito de lei, observa-se que diversos canais no YouTube e, inclusive, a própria TV aberta ainda não se adequaram à norma. Disponível em: http://agenciabrasil.ebc.com.br/geral/noticia/2017-08/proibicao-da-publicidade-infantil-reduziu-em-13receita-de-anunciantes. Acesso em: $17 \mathrm{dez} 2019$.
} 
Para ler o Pato Donald, de Dorfman e Mattelart (2003), e Sedução do Inocente, de Fredric Wertham (2005), apresentam os temores em torno da cooptação da infância por produtos da indústria cultural. Se Dorfman e Mattelart baseiam seus textos nos conceitos de colonização e alienação através do consumo dos desenhos e revistas Disney, Wetham associa delinquência juvenil aos quadrinhos. O olhar crítico direcionado às HQs foi, em grande parte, herdado pelos desenhos animados, já que os arquétipos apresentados poderiam ser localizados nas animações e programas infantis. A participação da criança no texto, assim, emerge apenas como ponto de partida para argumentações que potencializam a ideia de que ela deve ser entendida como uma figura incapaz de dialogar a partir das próprias experiências com o conteúdo proposto.

Esses olhares deram base para se perceberem as produções midiáticas que, a partir da concepção de criança como sendo um consumidor passivo, estabelece uma política de segmentação de público ao definir o conceito de "programas infantis" de forma bastante problemática. Desenhos animados, novelinhas infantis, game shows e outras produções, assim, constituem um esforço por parte das empresas midiáticas de aglutinar esses indivíduos ao redor de produtos específicos e excluí-los, consequentemente, de outros produtos, considerados "para adultos". Existe ao menos uma forte contradição nessa lógica, tendo em vista que não é raro crianças atuarem em programas destinados aos adultos - telenovelas, séries e filmes -, explicitando o fato de que a rigor elas podem trabalhar nesses produtos, mas não podem ou não devem consumi-los.

Em pesquisa anterior (HOLZBACH; NANTES; FERREIRINHO, 2019) já desenvolvemos um primeiro esforço para entender os critérios que definem socialmente, de maneira genérica, o que seria programa infantil. Nosso olhar não estava voltado para os limites da expressão, como propomos aqui, mas para as características que os programas infantis televisivos reúnem para serem reconhecidos enquanto tais. A partir da observação de produtos exibidos por 30 emissoras de 16 países de todos os continentes habitados, compreendemos que o conceito de programa infantil é definido pelas emissoras sob duas características principais:

- há indicação explícita de ser destinado às crianças, de zero a 12 anos. Isso pode acontecer na forma oralizada, ou seja, em caso de programas cujos apresentadores agem como se conversassem com crianças, e também a partir 
da narrativa e da estética dos programas, como em situações nas quais os cenários são lúdicos e tentam suprir expectativas que, entende-se, pertencem ao universo infantil;

- há publicidade direcionada às crianças e esta sempre aparece associada aos programas, seja no intervalo comercial ou no interior da narrativa.

O mapeamento realizado mostrou que os programas infantis podem ser categorizados em 1) desenhos animados, 2) ficção seriada (telenovelas e séries) e 3) programas de auditório. A reunião desses produtos em torno da chave "programa infantil" aconteceu conjuntamente com a cristalização da grade de programação das televisões abertas, que historicamente aglutinou as produções direcionadas às crianças em horários e faixas específicas. No Brasil, o primetime infantil instalou-se no horário matutino, de segunda a sábado, ainda na década de 1960, e assim permaneceu até o início dos anos 2000. A faixa era composta por diversas animações, algumas delas, inclusive, pensadas originalmente para o público adulto, como os Flinstones (1960), que era apresentado às 20:00h nos Estados Unidos, durante os anos 1960, mas no Brasil chegou a ser exibido às 10:45h, pela TV Tupi. No decorrer dos anos 1980, a entrada do Хои da Хиха (1986) na Rede Globo consolidou a faixa de horário matinal para as crianças na emissora, algo que seria mantido por quase 30 anos mesmo após diferentes empreitadas como TV Colosso (1992), Angel Mix (1996) e TV Globinho (2000) ${ }^{11}$, e que fora seguido, por exemplo, pelo SBT, que até hoje dedica esse horário a produtos destinados ao público infantil.

No Brasil, a instituição da programação infantil no horário matutino durante a semana teve em vista uma construção do cotidiano familiar na qual as crianças supostamente estariam em casa na parte da manhã e frequentariam a escola à tarde, ao passo que os pais estariam ou trabalhando fora ou cuidando dos afazeres domésticos. Trata-se de uma idealização da noção de família que segue moldes de uma classe média (branca) que desconsidera, dessa forma, a grande quantidade de crianças pobres que não

\footnotetext{
11 Para evitar o embate direto com a Globo, emissoras de menor audiência investiram em horários diferenciados para a programação, a exemplo Disney Club (SBT, 1997), originalmente exibido às 18:00h, Clube da Criança (Manchete, 1984), exibido inicialmente às 16:00h, e Agente G (Record, 1995), exibido às 20:00h. Entretanto, essas experiências aconteceram de forma pulverizada e, por isso, não consolidaram o público infantil nas faixas de horário em que foram exibidas.
} 


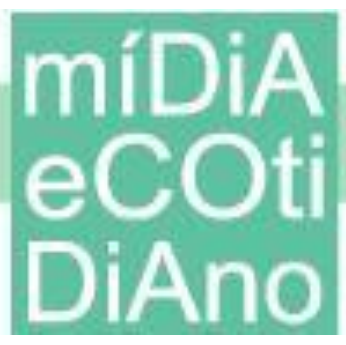

frequentavam a escola ou as famílias com integrantes desempregados, que em muitos casos dominavam os usos da televisão ao longo de todo o dia.

Essa política de segmentação de público infantil definida pela grade de programação tem sérias e ainda pouco compreendidas implicações ideológicas, entre as quais o enorme caráter eurocêntrico na definição de produção infantil (STEINBERG; KINCHELOE, 2001). O eurocentrismo caracteriza-se por um olhar de mundo endógeno e autocentrado, sustentado por inúmeros tipos de narrativas, que tem em vista o desenvolvimento e as caraterísticas da Europa instituídas na modernidade como referência de validação universal para as mais diferentes searas sociais (TANSEL, 2014). Além de hierarquizar os olhares de mundo de forma a inferiorizar o conhecimento produzido fora da Europa ocidental, a perspectiva eurocêntrica desconsidera as conexões socioculturais historicamente construídas mundialmente, o que tem sido fundamental para a perpetuação de estereótipos e silenciamentos. Existe atualmente um esforço para ultrapassar esse olhar, e é fundamental entender o lugar das produções infantis nesse contexto. Com efeito, o caráter eurocêntrico percebido nas produções infantis cristaliza o conceito de infância apoiado em um olhar que exclui uma gama de representações desenvolvidas fora da Europa moderna, como as representações raciais e de gêneros nãobinários. Nas animações infantis, por exemplo, o eurocentrismo é recorrentemente enfatizado na escolha das vozes e modos de falar das personagens e nos movimentos e uso de paletas de cores específicas, as quais priorizam esteticamente personagens brancos (DORNELLES, 2019). A estrutura de gênero explicitada nas histórias, por sua vez, é hegemonicamente formada pelo binarismo homem x mulher / menino x menina, especialmente quando se trata dos mocinhos e protagonistas das histórias. Isso acontece mesmo quando as personagens são antropomórficas: os animais agem no espectro do binarismo de gênero, reproduzindo comportamento "dos meninos" ou "das meninas". A paleta de cores frequentemente aciona tons de azul para meninos e tons de rosa para meninas, numa típica representação moderna que dicotomiza e silencia as problemáticas contemporâneas em torno da sexualidade humana.

Em termos narrativos, ainda no caso das animações, o tipo textual mais recorrente em longas-metragens infantis é a fábula, que se constitui a partir de condições de produção e instâncias de poder. De acordo com Veiga Neto (2015, p. 56): "governa- 


\section{míDiA

se a infância com o objetivo de conduzi-la para determinados 'lugares' numa cultura, para determinadas posições numa sociedade e para determinadas formas de vida já partilhada por aqueles que já estavam ali”. Com efeito, o cenário de formação identitária e construção de um mapa de navegabilidade histórico/social para as crianças tem como base estruturas hegemônicas as quais, numa perspectiva gramsciana, atuam na esfera de dominação através do direcionamento das leituras do mundo.

\section{Simbiose entre programas infantis e mercado}

Há, ainda, outro componente importante na intrincada construção social da infância: a relação construída entre os programas infantis e os produtos mercantis. Num estudo sobre comunicação de massa, Wilson Dizard (2001) comenta a estratégia da sinergia e a configuração do mercado de licenciados tendo como exemplo a Walt Disney. Um deles é o Rei Leão (1994), que alcançou uma lucratividade de 4,6 bilhões de dólares até 1997 somente pela utilização de imagens do filme em brinquedos, roupas e embalagens de alimentos, fora os lucros obtidos com a venda de VHSs e DVDs do original e das sequências. A sinergia passou a ser o objetivo de todas as produtoras, pois o lucro obtido com a venda de produtos é muito superior ao da bilheteria.

Desde pelo menos a década de 1980 , os produtos midiáticos direcionados a crianças consideram não apenas o produto em si, mas a maneira como ele pode ser explorado mercadologicamente ao longo e após a produção ir ao ar. Isso já foi observado por Stabile (2003) e também por Perea (2015), mas dentro de argumentos com poucas problematizações, visto que os objetos das autoras estavam mais relacionados à compreensão do desenvolvimento histórico de determinados produtos, como os desenhos animados. Pelo menos há 40 anos, a definição de programa infantil tem em vista necessariamente o seu potencial de exploração comercial por meio de produtos licenciados. Brinquedos de toda ordem, roupas, sapatos, produtos de higiene, ferramentas escolares, louça, malas de viagem e toda sorte de objetos dividem espaço com produtos midiáticos como peças de teatro, canais no YouTube, aplicativos e álbum de figurinhas que intentam prolongar ao infinito a experiência de fruição dos produtos infantis através de poderosas e inclementes estratégias comerciais. 
Isso acomete todas as categorias de produtos midiáticos pensados para as crianças, mesmo as muito pequenas, como é o caso da Galinha Pintadinha (HOLZBACH, 2018). A galinha azul que é protagonista de dezenas de vídeos inocentes no YouTube, direcionados principalmente aos bebês, é atualmente um império de licenciamentos. Em 2015 ela ficou em $89^{\circ}$ lugar num ranking das 150 maiores marcas do mundo em licenciamento, à frente de Sony, Volkswagen e Lamborghini ${ }^{12}$. Já se foram mais de 300 milhões de dólares em licenciamento que fazem com que a Galinha assuma, nesse levantamento, a melhor posição de uma marca brasileira. Isso incentivou os criadores, Juliano Prado e Marcos Luporini, a apresentarem a Galinha Pintadinha em feiras de licenciamento como importante estratégia de crescimento econômico.

A intensa relação existente entre programas infantis e as estratégias comerciais de consumo potencializa o caráter mercantil que não pode ser ignorado ao refletirmos sobre a construção do conceito de infância na contemporaneidade. Mais do que produtos disponíveis para consumo, os produtos licenciados se transformam em parte integrante da experiência de fruição de desenhos, novelinhas e séries, o que aumenta em progressão geométrica o caráter excludente do conceito de programa infantil que estamos debatendo neste trabalho. Se vivemos em um contexto midiático que exclui um enorme número de crianças do consumo do que se considera como sendo programa infantil, essa exclusão toma proporções ainda mais intensas quando englobamos os produtos mercantis que orbitam esses programas. Para além do problema evidente de a criança entrar em uma loja e não poder adquirir o brinquedo do seu desenho animado favorito, esse elemento oferece um grande potencial de exclusão ao reconfigurar um conjunto de experiências que perpassam o dia-a-dia da criança, desde a escolha da pasta e da escova de dentes passando pelo prato e pelos talheres do almoço e chegando à mochila e aos tênis usados para ir para a escola, por exemplo.

\section{Considerações finais}

As ciências humanas já sabem, desde pelo menos a publicação, em 1867, de $O$ Capital, de Karl Marx, que existe um enorme caráter de exclusão na maneira como a

\footnotetext{
${ }^{12}$ Dados publicados pela Forbes. Disponível em: <http://abre.ai/ar2B>. Acesso em: 08 nov. 2019.
} 


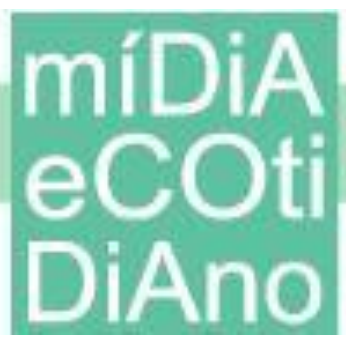

sociedade moderna formatou suas características. Essa exclusão tem em vista os usos econômicos e valores simbólicos construídos em torno dos bens de consumo, entre eles, enfatizamos aqui os produtos midiáticos. Considerando que o conceito de infância é resultado de um processo histórico culminado na modernidade capitalista, é evidente que os produtos midiáticos e mercantis perpassam esse conceito desde o seu cerne. Destacamos, neste artigo, um elemento que consideramos ser basilar na compreensão da infância contemporânea nesse contexto - os programas infantis - através de uma chave específica de leitura, que enfatiza o caráter excludente desses programas.

A partir disso, localizamos dois importantes elementos que atuam impondo limites na definição de programa infantil. Primeiramente temos o olhar eurocêntrico instituído tanto na estrutura de exibição dos programas infantis - a partir da grade de programação - quanto na estrutura interna desses programas. Enfatizamos a narrativa e a estética desses produtos como elementos nevrálgicos para compreensão desse olhar, que exclui em grande medida representações que fogem do padrão moderno europeu. Em segundo lugar, é premente consideramos a relação simbiótica existente entre os programas infantis e a mercantilização de bens de consumo. Cada vez mais, a experiência de fruição dos programas infantis se estrutura a partir de estratégias conscientemente formatadas de venda de produtos que orbitam e atravessam a experiência midiática infantil. O papel social dos programas infantis, sustentamos, só é compreendido com amplitude se levarmos em conta a maneira como o universo de produtos mercantis se relaciona com os produtos midiáticos.

Finalmente, sustentamos que os problemas destacados no caráter excludente do que se entende como programa infantil não significam, todavia, que as crianças sejam passivas a essas questões. Acreditamos que elas dialogam e reagem aos mecanismos de opressão configurados nos programas infantis e na (cruel, excludente e) sólida cultura do consumo. Precisamos, agora, entender melhor quais estratégias elas acionam e de que maneira o comportamento delas reconfigura e questiona o lugar hegemônico dos produtos infantis midiatizados. Este é um dos desafios que almejamos ainda realizar. 


\section{midiA
gCOA
DAAnd}

\section{Referências}

BRAGAGLIA, Ana Paula; FERREIRA, André Luiz. Os youtubers mirins e a felicidade através do consumo. Temática, v. 12. n. 12, p. 1-17, 2016.

BUONANNO, Milly. The age of television: experiences and theories. Brixton-UK/ ChicagoUS: Intellect, 2008.

CERTEAU, Michel de. A invenção do cotidiano: Artes de fazer. Petrópolis: Vozes, 1994.

COHN, Clarice. Antropologia da criança. Rio de Janeiro: Zahar, 2010.

CORRÊA, Luciana. Geração YouTube: um mapeamento sobre o consumo e a produção de vídeos por crianças. 0 a 12 anos - Brasil - 2005/2015. São Paulo: ESPM/MediaLab, 2016. Disponível em: <https://criancaeconsumo.org.br/wp-content/uploads/2018/09/MediaLab_Luciana_Correa_2016.pdf>. Acesso em: 27 jan. 2020.

COUTINHO, Luciana. A adolescência na contemporaneidade: ideal cultural ou sintoma social? Pulsional Revista de Psicanálise, v. 17, n. 181, p. 13-19, 2005.

DIZARD, Wilson. Comunicação de massa na era da informação: a nova mídia. Rio de Janeiro: Zahar, 2001.

DORFMAN, Ariel; MATTELART, Armand. Para ler o Pato Donald. 5 ed. São Paulo: Editora Paz e Terra, 2003.

DORNELLES, Wagner. O que se cala: panorama da representação negra nas animações mainstream. (Dissertação mestrado em Comunicação) Programa de Pós-graduação em Comunicação, Universidade Federal Fluminense, Niterói-RJ, 2019.

EMERA, Simone de Oliveira. Letramento digital na educação infantil. Caxias do Sul: Congresso de pesquisa e extensão da FSG, n. 11, p.111-222, mai. 2014.

GONÇALVES, Márcio. Wikipédia: discurso e validade da informação. Tese (Doutorado em Comunicação). Programa de Pós-graduação em Ciência da Informação, Universidade Federal do Rio de Janeiro, Rio de Janeiro-RJ, 2014.

HELLER, Agnes. O cotidiano e a história. 8. ed. São Paulo: Paz e Terra, 2011.

HOLZBACH, Ariane. Para pequenos grandes espectadores: a produção televisiva brasileira direcionada a crianças pequenas a partir do caso da Galinha Pintadinha. E-Compós, v. 21, n. 2, p. 1-22, mai./ago. 2018.

HOLZBACH, Ariane; NANTES, Joana D`Arc; FERREIRINHO, Gabriel. Onde estão as crianças? Uma investigação mundial da programação infantil na TV aberta. In: ENCONTRO ANUAL DA COMPÓS, 28. Anais... PUC-RS, Porto Alegre, jun. 2019. Disponível em: <http://www.compos.org.br/biblioteca/trabalhos_arquivo_LXL1CESX2ETXCCMJRRPT_28_7 725_21_02_2019_12_32_15.pdf>. Acesso em: 27jan. 2020.

PEREA, Katia. Girls Cartoon second wave: transforming the genre. Animation: An Interdisciplinary Journal, v. 10, n. 3, p. 189-204, 2015. 
STABILE, Carol; HARRISON, Mark (Orgs.). Prime Time Animation: television animation and American culture. New York: Routledge, 2003.

STEINBERG, Shirley R.; KINCHELOE, Joe L. (Orgs.). Cultura infantil: a construção corporativa da infância. Rio de Janeiro: Civilização Brasileira, 2001.

TANSEL, Cemal Burak. Defending silence? Marxism, international historical sociology and the spectre of eurocentrism. European Journal of International Relations, v. 1, n. 25, p.3-26, 2014.

TOMAZ, Renata Cristina de Oliveira. O que você vai ser antes de crescer? youtubers, infância e celebridade. (Tese de doutorado em Comunicação). Programa de Pós-graduação em Comunicação e Cultura, Universidade Federal do Rio de Janeiro, Rio de Janeiro-RJ, 2017.

VEIGA-NETO, Alfredo. Por que governar a infância. In: VEIGA-NETO, A. (Org.). Michel Foucault: o governo da infância. São Paulo: Autêntica, 2015, p. 49-56.

WERTHAM, Fredric. Seduction of the innocent. Laurel: Main Road Books, 2005. 